\title{
EFEITOS DA RODA COMPACTADORA DE SEMEADORAS SOB CARGAS VERTICAIS NA DEFORMAÇÃO DO SOLO COM DOIS TEORES DE ÁGUA
}

\author{
ROUVERSON P. DA SILVA ${ }^{1}$, CARLOS E. A. FURLANI ${ }^{2}$, AFONSO LOPES ${ }^{3}$, \\ ALESSANDRO NASCIMENTO ${ }^{4}$, FELIPE T. DA CAMARA ${ }^{4}$
}

\begin{abstract}
RESUMO: O presente trabalho foi conduzido na Pista de Ensaios de Semeadura do Laboratório de Máquinas e Mecanização Agrícola (LAMMA) da UNESP/Jaboticabal - SP, para o estudo da ação da roda compactadora de semeadoras sob cargas verticais, na deformação do solo, com dois teores de água. Os tratamentos consistiram da combinação de dois teores de água e seis cargas verticais, totalizando 12 tratamentos, com três repetições, em dois ensaios, analisando-se a resistência mecânica do solo à penetração e a deformação do solo provocada pela roda compactadora. A roda compactadora utilizada era de alumínio, com massa de $6,4 \mathrm{~kg}, 40 \mathrm{~cm}$ de diâmetro e $10 \mathrm{~cm}$ de largura, sob a ação de cargas verticais de 63; 161; 259; 357; 455 e 553 N, obtidas acoplando-se lastros de chumbo sobre a roda compactadora, sendo os teores de água do solo de 15,4 e 9,2\%. Os resultados permitem concluir que o teor de água do solo tem grande influência na deformação e compactação do solo, que aumentam proporcionalmente com as cargas verticais sobre a roda compactadora, e que, quanto maior o teor de água do solo, mais suscetível o mesmo fica à compactação e deformação.
\end{abstract}

PALAVRAS-CHAVE: canal de solo, semeadura, resistência do solo à penetração.

\section{EFFECT OF SEEDERS PRESS WHEEL ACTION UNDER LOADS IN THE SOIL DEFORMATION IN TWO MOISTURE CONTENTS}

\begin{abstract}
The present work was leading in the sowing assays track at the Laboratório de Máquinas e Mecanização Agrícola (LAMMA), UNESP/Jaboticabal-SP, Brazil, where it was studied the press wheel action under loads in soil deformation with two moisture contents. The treatments consisted in the combination of two moisture contents, and six loads, totalizing twelve treatments with three repetitions. The following parameters were analyzed: soil mechanical resistance to penetration and the analysis of the soil deformation caused by the press wheel in static and dynamic testing. The press wheel used was of aluminum, with $6.4 \mathrm{~kg}$ mass, $40 \mathrm{~cm}$ diameter and $10 \mathrm{~cm}$ width. The load used was of $63 ; 161 ; 259 ; 357 ; 455$ e $553 \mathrm{~N}$, gotten by the connection of ballasts on the press wheel. The tested soil moisture was $15.4 \%$, and $9.2 \%$. The results allow concluding that the soil moisture has great influence on the soil deformation and compacting. The increase of the loads on the press wheel is directly proportional to soil deformation and compacting, and the bigger the soil moisture is, more susceptible is the soil to the compacting and deformation.
\end{abstract}

KEYWORDS: soil bin, sowing, soil mechanical resistance to penetration.

\section{INTRODUÇÃO}

As rodas compactadoras têm a função de melhorar o contato entre o solo e a semente, por meio da aplicação de pressão lateral e/ou sobre o sulco de semeadura, provocando leve compactação e deixando o solo diretamente sobre as sementes, solto o suficiente para facilitar a emergência das plântulas. Além dessa pressão, outros fatores a serem considerados na operação de semeadura são os teores de água do solo e o tipo de solo, dentre outros.

\footnotetext{
${ }^{1}$ Eng ${ }^{\circ}$ Agrícola, Prof. Assistente Doutor, Departamento de Engenharia Rural, UNESP, Jaboticabal -SP, Fone: (0XX16) 3209.2637, rouverson@fcav.unesp.br

${ }^{2}$ Eng ${ }^{\circ}$ Agrônomo, Prof. Adjunto, Departamento de Engenharia Rural, UNESP, Jaboticabal - SP.

${ }^{3}$ Eng ${ }^{\mathrm{O}}$ Agrícola, Prof. Adjunto, Departamento de Engenharia Rural, UNESP, Jaboticabal - SP.

${ }^{4}$ Eng ${ }^{\circ}$ Agrônomo, Departamento de Engenharia Rural, UNESP, Jaboticabal - SP.

Recebido pelo Conselho Editorial em: 11-1-2006
}

Aprovado pelo Conselho Editorial em: 21-6-2006

Eng. Agríc., Jaboticabal, v.26, n.2, p.511-519, maio/ago. 2006 
Muitas são as variáveis presentes no projeto de uma semeadora e algumas delas, como a pressão da roda compactadora e a profundidade de semeadura, além de outros fatores inerentes ao solo, como o teor de água, podem ser limitantes para a obtenção de resultados de pesquisa. Segundo BALASTREIRE (1990), em grande parte das semeadoras disponíveis no Brasil, pode-se realizar o controle da compactação sobre a semente por meio das rodas compactadoras ou rodas de controle de profundidade. As rodas compactadoras têm a função de aumentar o contato das sementes com o solo para melhorar a absorsão de água, garantindo melhor germinação (PACHECO, 1994).

HUMMEL et al. (1981), trabalhando com diferentes tipos de rodas compactadoras na semeadura de soja, afirmaram que o desenho e a operação da roda compactadora apresentaram considerável influência, benéfica ou não, sobre o ambiente do solo em torno da semente e que seu efeito depende do nível de pressão e do desenho da roda, do teor de água e do tipo do solo e das condições climáticas no período entre a semeadura e a emergência.

FURLANI et al. (2001), combinando três profundidades de semeadura de milho com quatro níveis de compactação do solo sobre as sementes, não encontraram influência desses fatores sobre o número médio de dias para emergência das plântulas. Por outro lado, a resistência mecânica do solo à penetração aumentou com a utilização de maiores cargas sobre a roda compactadora.

Ao estudar o efeito de três rodas compactadoras, variando as cargas verticais e a profundidade de semeadura de milho (Zea mays L.), SILVA (2002) verificou que o nível de carga aplicado ao solo pelas rodas compactadoras, a geometria das rodas e a profundidade de semeadura podem provocar alterações no ambiente físico do solo. $\mathrm{O}$ autor observou, ainda, que as rodas com maior área de contato com o solo proporcionaram maiores valores do teor médio de água do solo e da temperatura do solo no período de emergência do milho.

Segundo MACHADO et al. (1993), determinações do contorno da superfície do solo são importantes em atividades agrícolas para a avaliação da capacidade de armazenamento de água, da resistência da superfície do solo a danos provocados pelo preparo para a semeadura e da resistência do solo à mobilização por máquinas.

SILVA et al. (2005), trabalhando com três modelos de rodas compactadoras, variando as cargas verticais, verificaram que, para dois modelos de rodas compactadoras em "V", houve compactação lateral do solo, enquanto para o modelo de roda convexa a pressão foi exercida de forma direta sobre a linha de semeadura, observando, ainda, que para um dos modelos de roda compactadora em "V", cargas verticais no intervalo de 75 a $325 \mathrm{~N}$ provocaram a elevação central do solo na linha de semeadura. Entretanto, para cargas acima de $325 \mathrm{~N}$, houve a redução da elevação central, com ocorrência de compactação direta sobre a linha de semeadura.

Procurando contribuir para a realização de estudos relacionados às interações do sistema máquina-solo durante a semeadura, este trabalho teve por objetivo estudar o efeito de roda compactadora sobre o solo, em situação estática e dinâmica, submetida a seis níveis de carga vertical, sob dois teores de água no solo, utilizando-se de um canal de solo desenvolvido para a realização de ensaios de semeadura.

\section{MATERIAL E MÉTODOS}

O experimento foi conduzido na Pista de Ensaios de Semeadura do Laboratório de Máquinas e Mecanização Agrícola (LAMMA) da UNESP/Jaboticabal - SP, localizada nas coordenadas geodésicas: latitude $21^{\circ} 15^{\prime} \mathrm{S}$ e longitude $48^{\circ} 18^{\prime} \mathrm{W}$, com altitude média de $560 \mathrm{~m}$ e clima do tipo Cwa (subtropical), de acordo com a classificação de Köeppen. O solo da área experimental foi classificado por ANDRIOLI \& CENTURION (1999) como Latossolo Vermelho Eutroférrico típico, A moderado, textura argilosa e relevo suave ondulado, conforme o Sistema Brasileiro de Classificação de Solos (EMBRAPA, 1999). 
A pista de ensaios onde foi conduzido o trabalho, é constituída por duas faixas de solo planas, dispostas na direção leste-oeste e delimitadas por trilhos, medindo cada uma $1,5 \mathrm{~m}$ de largura por $22 \mathrm{~m}$ de comprimento. Cada parcela do experimento consistiu em 1,5 m de largura por 2,5 m de comprimento, para os ensaios em caráter dinâmico, e $1,5 \mathrm{~m}$ de largura por $1 \mathrm{~m}$ de comprimento, para os ensaios em caráter estático. Sobre os trilhos desloca-se à velocidade de $4 \mathrm{~km} \mathrm{~h}^{-1}$, um trole elétrico ao qual é possível acoplar acessórios como: plaina niveladora, sulcador, equipamentos para irrigação e roda compactadora, permitindo desenvolver ensaios de alta precisão em condições simuladas de campo.

O preparo do solo foi realizado com enxada rotativa, tipo faca veloz, acoplada a um trator de rabiças da marca TOBATTA, com potência de 9,42 kW (12 cv), modelo M 90, e posteriormente nivelado com plaina niveladora acoplada ao trole.

A roda compactadora utilizada era de alumínio, com massa de $6,4 \mathrm{~kg}, 40 \mathrm{~cm}$ de diâmetro e $10 \mathrm{~cm}$ de largura. As massas utilizadas sobre a roda compactadora foram obtidas acoplando-se lastros de chumbo de $0 ; 10 ; 20 ; 30 ; 40$ e $50 \mathrm{~kg}$, resultando em cargas verticais de $63 ; 161 ; 259 ; 357$; 455 e $553 \mathrm{~N}$, respectivamente.

Ao final de cada parcela, após o deslocamento do trole, a roda compactadora foi colocada em posição estática, com a devida massa, por 10 segundos. Foram realizadas análises de resistência mecânica do solo à penetração e deformação com o minipenetrômetro e o perfilômetro, respectivamente, nas áreas dos ensaios estático e dinâmico.

$\mathrm{O}$ experimento foi desenvolvido em delineamento inteiramente casualizado, em esquema fatorial $2 \times 6$, com dois teores de água e seis cargas verticais, totalizando 12 tratamentos, com três repetições, descritos na Tabela 1 , sendo realizados dois ensaios: estático e dinâmico.

TABELA 1. Descrição dos tratamentos.

\begin{tabular}{ccc}
\hline Tratamento & Carga Vertical $(\mathrm{N})$ & Teor de Água $(\%)$ \\
\hline C1U1 & 63 & 15,4 \\
C2U1 & 161 & 15,4 \\
C3U1 & 259 & 15,4 \\
C4U1 & 357 & 15,4 \\
C5U1 & 455 & 15,4 \\
C6U1 & 553 & 15,4 \\
C1U2 & 63 & 9,2 \\
C2U2 & 161 & 9,2 \\
C3U2 & 259 & 9,2 \\
C4U2 & 357 & 9,2 \\
C5U2 & 455 & 9,2 \\
C6U2 & 553 & 9,2 \\
\hline
\end{tabular}

Os teores de água do solo foram determinados segundo metodologia descrita pela EMBRAPA (1979), retirando-se cinco amostras de solo por pista, na profundidade de 0 a $10 \mathrm{~cm}$, imediatamente após a passagem da roda compactadora. Para a obtenção dos teores de água desejados, aplicou-se, inicialmente, lâmina d'água diária de $10 \mathrm{~mm}$ até que o solo atingisse a capacidade de campo. Posteriormente, aguardou-se a perda d'água por evaporação, monitorando-se o teor de água do solo diariamente.

Para a análise da resistência mecânica do solo à penetração, foram feitas leituras com três repetições, na profundidade de $0,05 \mathrm{~m}$, ao longo da área em que a roda compactadora passou ou esteve parada.

A partir das leituras do minipenetrômetro, calculou-se a resistência mecânica à penetração por meio da eq.(1). 


$$
\mathrm{Rp}=\mathrm{L} \mathrm{K}
$$

em que,

$\mathrm{Rp}$ - resistência do solo à penetração, $\mathrm{kgf} \mathrm{cm}^{-2}$;

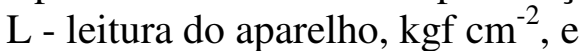

$\mathrm{K}$ - fator unitário de conversão, 0,1023 .

Para a análise da deformação do solo provocada pela roda compactadora em ensaio estático e dinâmico, foi utilizado um perfilômetro, que consiste de uma armação de madeira, dotada de varetas de metal espaçadas de um centímetro e dispostas verticalmente. Ao fundo do aparelho, existe um papel graduado em centímetros, onde é possível fazer a leitura individual da profundidade de cada vareta.

O perfilômetro foi colocado transversalmente à direção de deslocamento da roda compactadora, logo após a passagem do trole, sendo anotadas as leituras correspondentes de cada vareta.

A determinação da pressão exercida pela roda compactadora ocorreu a partir da eq.(2), descrita por MIALHE (1980), para cálculo da área de contato roda-solo em condições de deslocamento.

$$
\mathrm{S}=1,005 \mathrm{rb}
$$

em que,

$$
\begin{aligned}
& \mathrm{S} \text { - área de contato roda-solo, } \mathrm{m}^{2} ; \\
& \mathrm{r} \text { - raio da roda, } \mathrm{m}, \mathrm{e} \\
& \mathrm{b} \text { - largura da roda, } \mathrm{m} .
\end{aligned}
$$

Conhecendo-se a carga estática aplicada e a área de contato entre a roda e o solo, determinouse a pressão exercida pela roda compactadora sobre o solo. Por meio de regressão potencial para os diagramas pressão-deformação, obtiveram-se, então, as equações que correlacionam a pressão exercida sobre o solo, com a máxima deformação provocada para cada teor de água.

As equações foram obtidas a partir da expressão empírica desenvolvida por Bernstein e modificada por BEKKER (1956):

$$
\mathrm{P}_{\max }=\mathrm{k} \mathrm{z}^{\mathrm{n}}
$$

em que,

$\mathrm{P}_{\max }$ - pressão máxima exercida sobre o solo, $\mathrm{kPa}$;

$\mathrm{k}$ - coeficiente de proporcionalidade;

z - máxima deformação do solo, mm, e

$\mathrm{n}$ - coeficiente de deformação do solo.

De acordo com VIEIRA (1982), os valores de $\mathrm{k}$ e $\mathrm{n}$ podem ser estimados por regressão linear ou não-linear, e com essa última se obtêm melhores resultados.

\section{RESULTADOS E DISCUSSÃO}

Na Figura 1, pode-se observar uma inversão da resistência do solo à penetração, à medida que as cargas verticais foram aumentando. Inicialmente, quando as cargas verticais de $63 \mathrm{~N}$ foram aplicadas, a resistência do solo à penetração com teor de água de 9,2\% era maior, comparada ao solo com teor de água de 15,4\%. Entretanto, à medida que aumentaram as cargas verticais, a resistência do solo à penetração nas parcelas com teor de água de $9,2 \%$ foi menor em comparação aos tratamentos com teor de água a $15,4 \%$. Como as medidas de resistência à penetração foram feitas logo após a passagem da roda compactadora, observa-se que o maior teor de água do solo, associado às maiores cargas verticais, propiciou compactação do solo relativamente maior. 


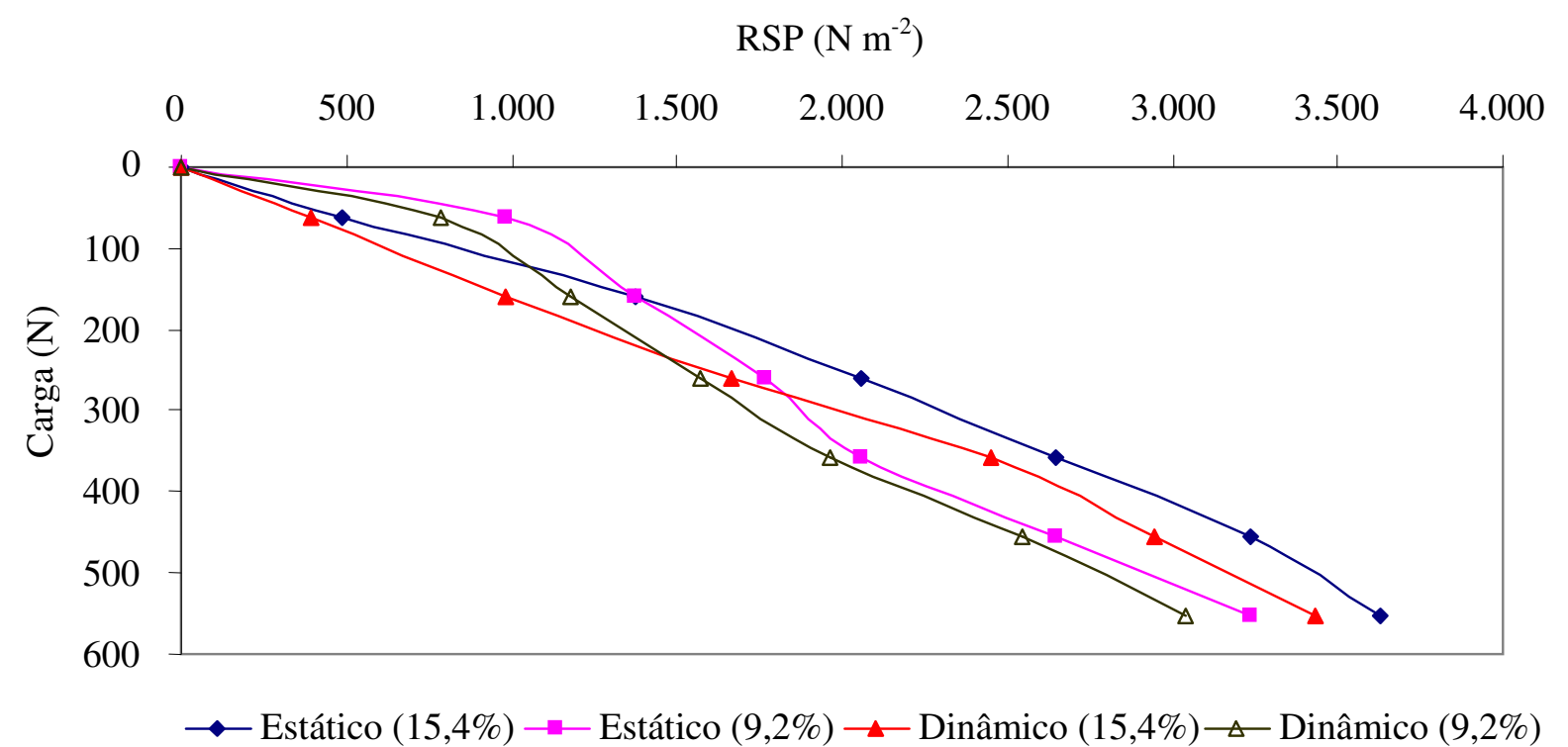

FIGURA 1. Resistência do solo à penetração (RSP) em função do teor de água e da carga aplicada.

Nas Figuras 2 e 3, são apresentadas as regressões obtidas, nas quais se pode observar que os solos com teor de água de $15,4 \%$ estão mais suscetíveis à deformação em comparação ao solo com teor de água de 9,2\%, para a mesma pressão aplicada. Quando a roda compactadora aplicou a mesma pressão por mais tempo (tratamentos em situação estática), a deformação do solo foi maior em comparação aos resultados obtidos em caráter dinâmico.

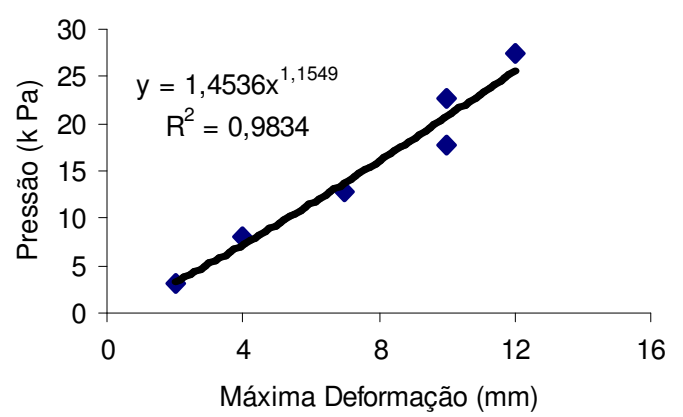

(a)

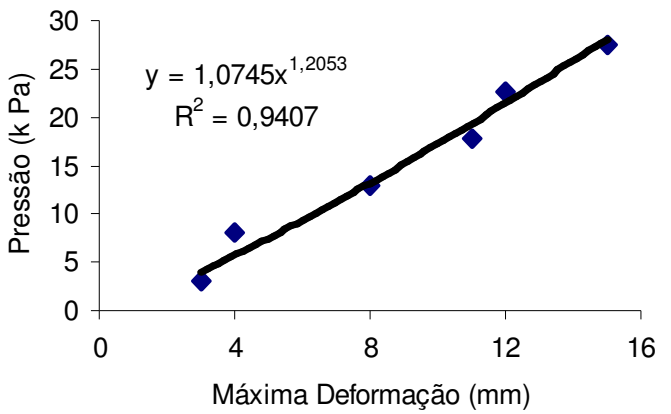

(b)

FIGURA 2. Pressão e deformação do solo para a roda compactadora com teor de água do solo de 9,2\%. a) Ensaio dinâmico; b) Ensaio estático.

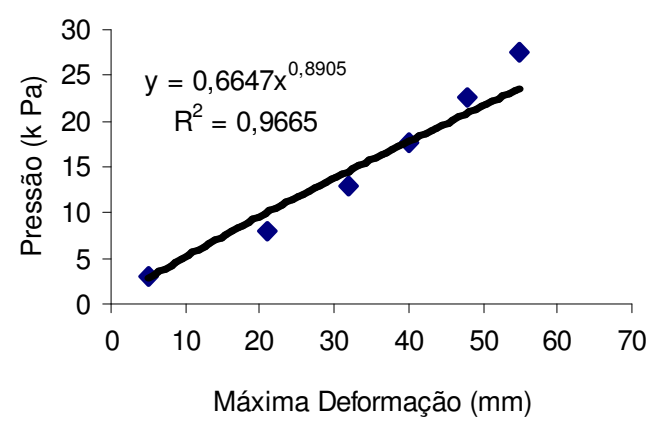

(a)

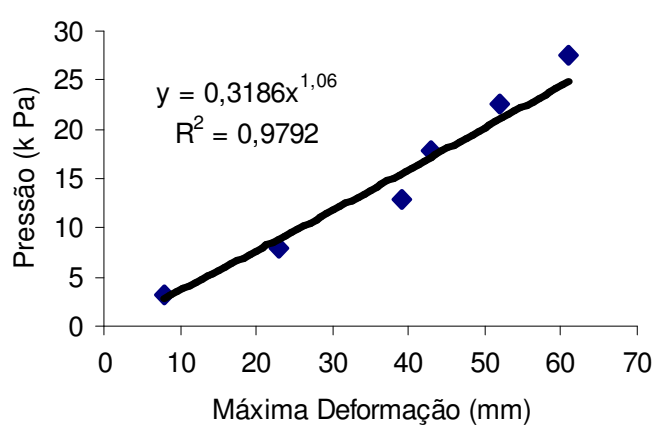

(b)

FIGURA 3. Pressão e deformação do solo para a roda compactadora com teor de água do solo de 15,4\%. a) Ensaio dinâmico; b) Ensaio estático. 
Comparando-se as equações de regressão obtidas para os dados experimentais com a expressão apresentada por BEKKER (1956), obtiveram-se os coeficientes de proporcionalidade (k) e de deformação do solo (n) para a pista de ensaios, apresentados na Tabela 2.

TABELA 2. Valores da máxima deformação (z) e dos coeficientes de proporcionalidade (k), de deformação do solo (n) e de determinação $\mathrm{R}^{2}$.

\begin{tabular}{lrcccc}
\hline Ensaios & $\begin{array}{c}\text { Teor de Água } \\
\%\end{array}$ & $\mathrm{k}$ & $\mathrm{n}$ & $\mathrm{z}$ & $\mathrm{R}^{2}$ \\
\hline Estático & 15,4 & 0,32 & 1,06 & 61 & 0,9792 \\
Dinâmico & 15,4 & 0,66 & 0,89 & 55 & 0,9665 \\
Estático & 9,2 & 1,07 & 1,21 & 15 & 0,9407 \\
Dinâmico & 9,2 & 1,45 & 1,15 & 12 & 0,9834 \\
\hline
\end{tabular}

HARRIS (1971) afirmou que o parâmetro (n) apresenta valores entre 0 e 1 para a maioria dos solos agricultáveis. Por outro lado, MAH (1980) obteve valores de (n) menores que 1 para solo arenoso de Janaúba e maiores que 1 para solo argiloso de Viçosa, enquanto SILVA et al. (2005), trabalhando com três modelos de rodas compactadoras, variando as cargas verticais em Latossolo Vermelho Distrófico, encontraram valores médios dos coeficientes de proporcionalidade (k) próximos a 0 e de deformação (n) maiores que 1,5.

De acordo com ASHIBURNER \& SIM (1984), a resistência de um solo e a sua deformação por compressão ou por cisalhamento são determinadas pelas resistências coesiva e friccional. Eles afirmam, ainda, que esses parâmetros $(\mathrm{k})$ e (n) podem sofrer variações consideráveis devido ao teor de água do solo e ao tamanho de agregados. Logo, diferentes valores dos coeficientes (k) e (n) podem ser encontrados devido aos vários fatores que afetam esses parâmetros, como, por exemplo, a granulometria e o teor de água do solo. Nas Figuras 4 a 7, são apresentados os perfis do solo obtidos a partir das medidas do perfilômetro.

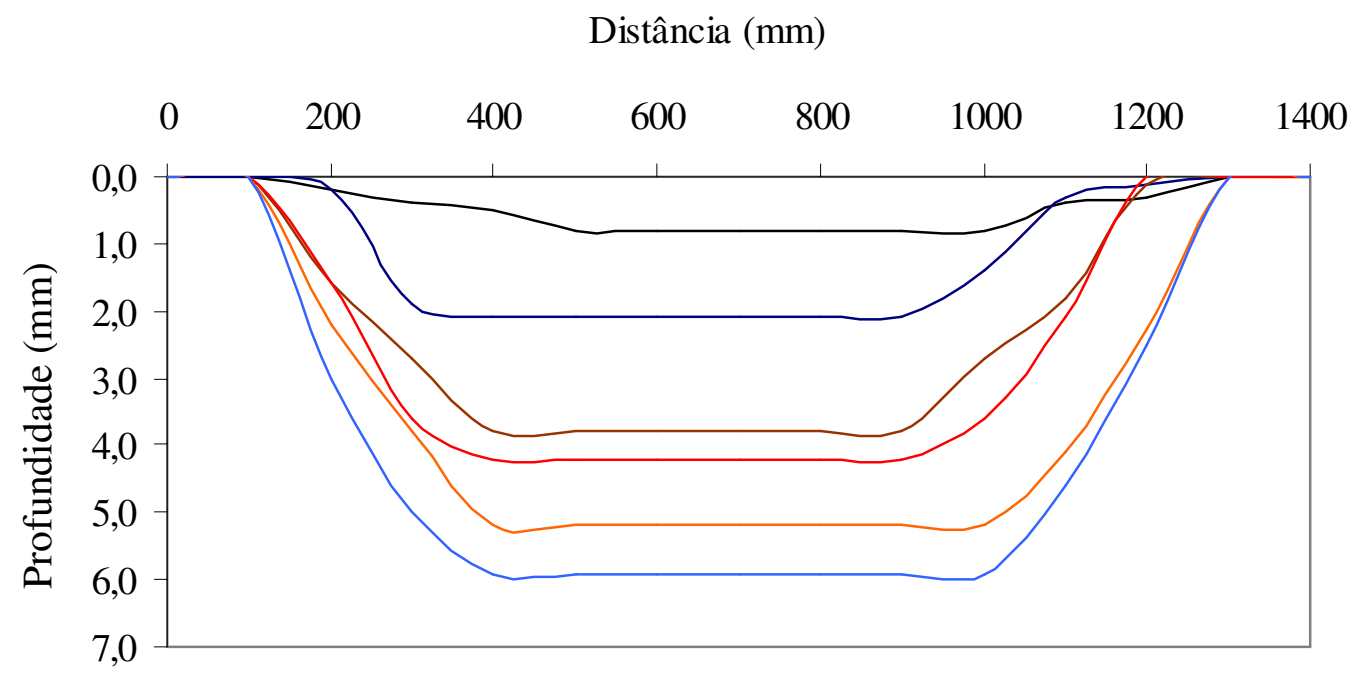

Ensaio Estático

$-\mathrm{C} 1 \mathrm{U} 1-\mathrm{C} 2 \mathrm{U} 1-\mathrm{C} 3 \mathrm{U} 1-\mathrm{C} 4 \mathrm{U} 1-\mathrm{C} 5 \mathrm{U} 1-\mathrm{C} 6 \mathrm{U} 1$

FIGURA 4. Perfil do solo para o ensaio estático na umidade de $15,4 \%$, em função das cargas verticais aplicadas. 


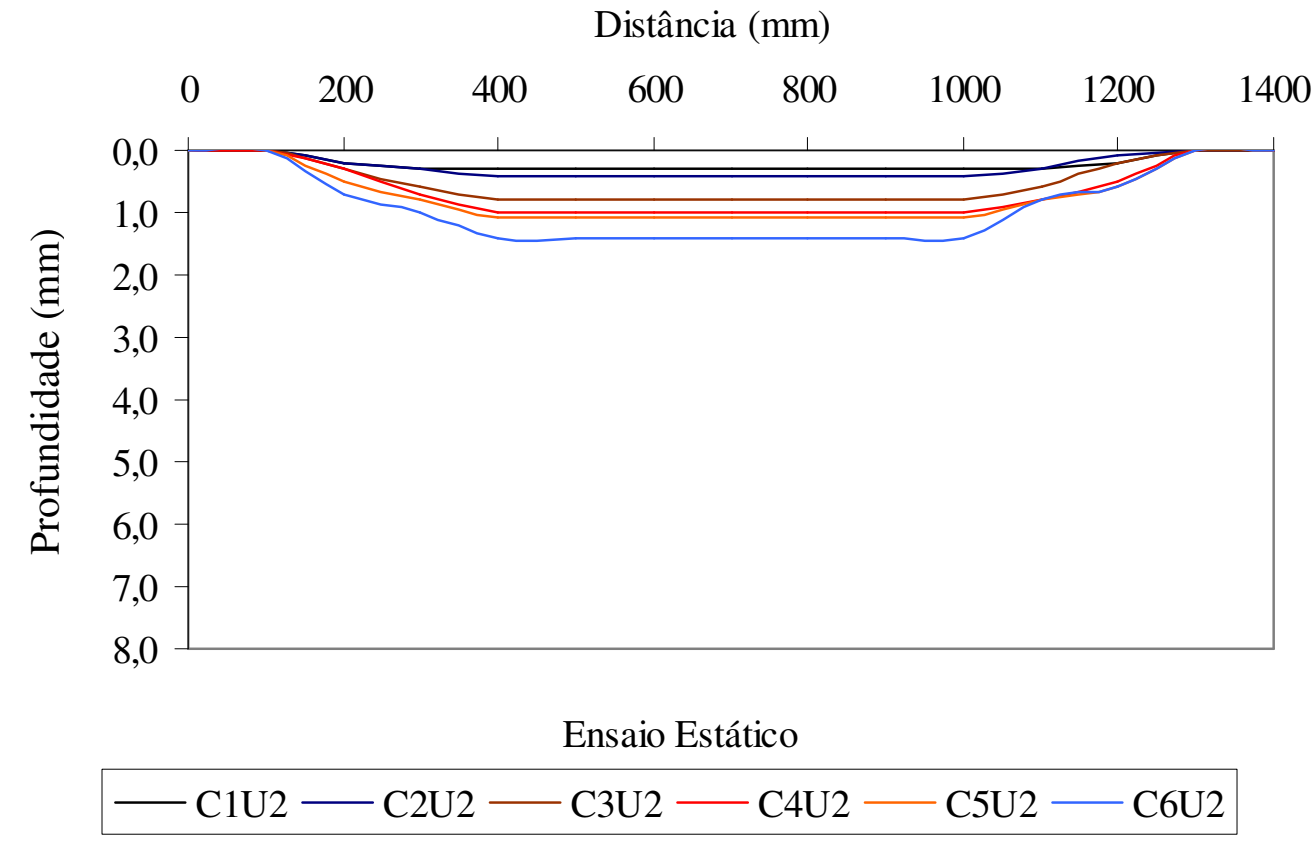

FIGURA 5. Perfil do solo para o ensaio estático na umidade de 9,2\%, em função das cargas verticais aplicadas.

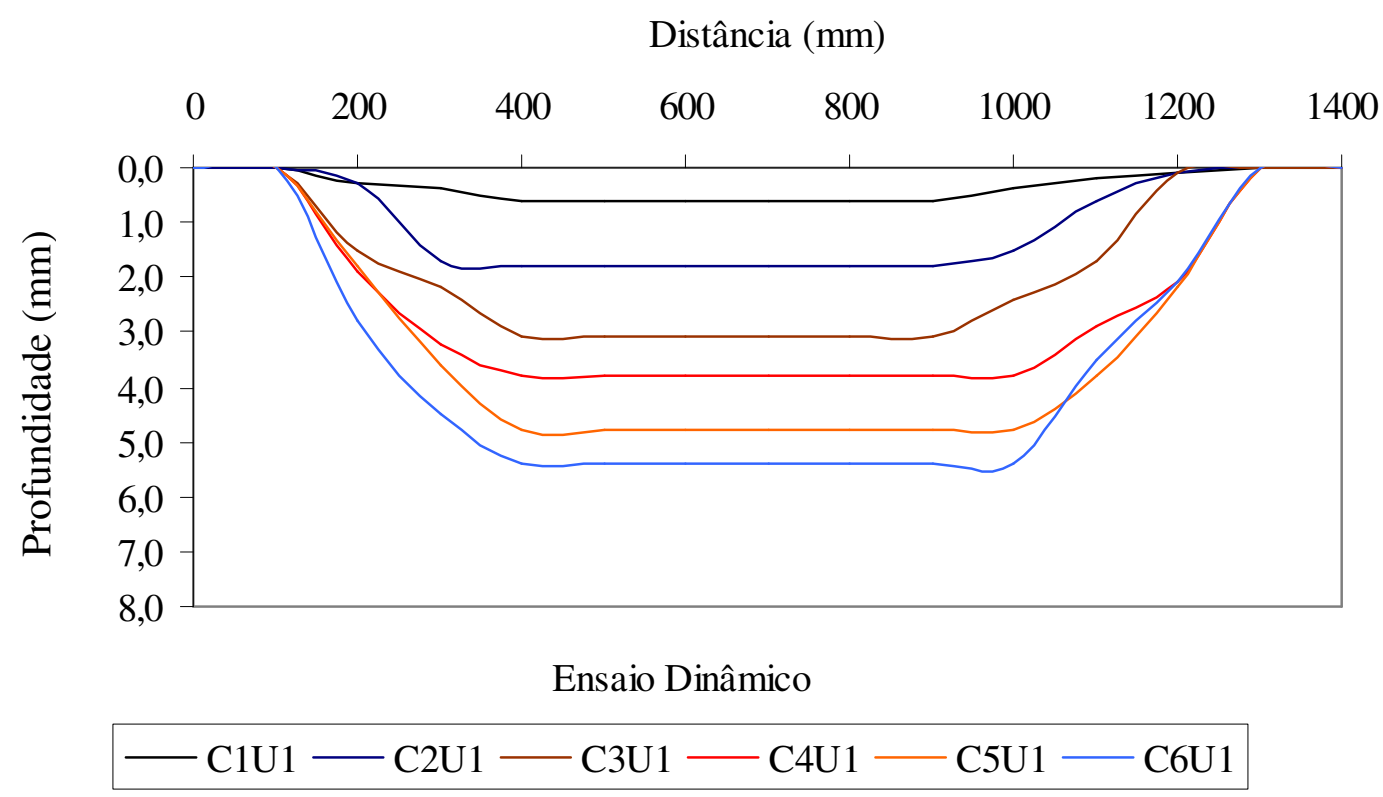

FIGURA 6. Perfil do solo para o ensaio dinâmico na umidade 15,4\%, em função das cargas verticais aplicadas. 


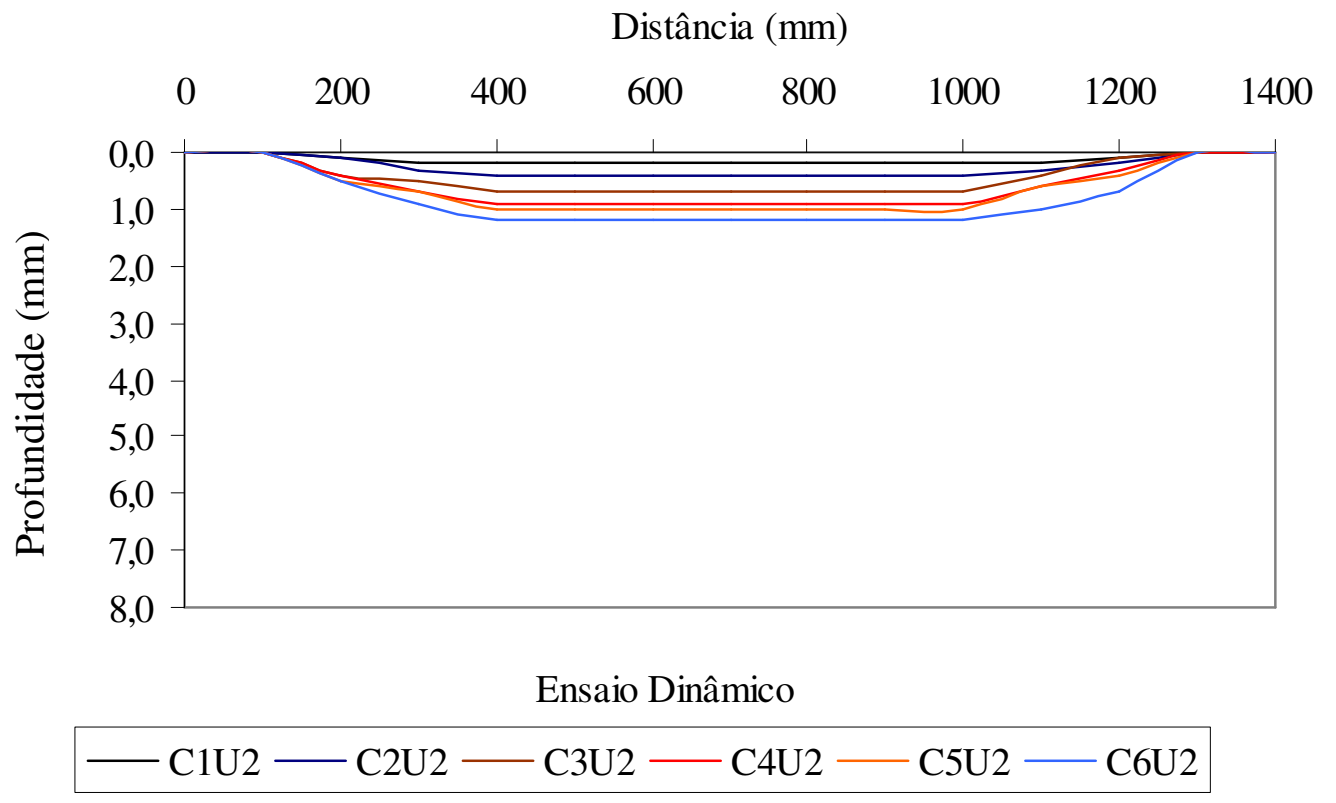

FIGURA 7. Perfil do solo para o ensaio dinâmico na umidade 9,2\%, em função das cargas verticais aplicadas.

Observa-se que a deformação foi mais intensa no solo com maior teor de água e foi maior quando as cargas verticais aplicadas aumentaram. VIEIRA (1982) afirma que a mesma pressão aplicada a solos de diferentes naturezas e teores de água provoca diferentes deformações. MAH (1980) aponta o teor de água do solo como o fator que mais influi no comportamento mecânico do solo.

Dessa maneira, durante a operação da semeadura, não basta apenas conhecer a carga vertical que será aplicada na roda compactadora, mas também o teor de água do solo.

\section{CONCLUSÕES}

A roda compactadora deixada parada sobre o solo provocou maior compactação e deformação do que em movimento.

A deformação e a compactação do solo são diretamente proporcionais ao aumento das cargas verticais sobre a roda compactadora.

O solo fica mais suscetível à compactação e deformação com o aumento do seu teor de água.

\section{REFERÊNCIAS}

ANDRIOLI, I.; CENTURION, J.F. Levantamento detalhado dos solos da Faculdade de Ciências Agrárias e Veterinárias de Jaboticabal. In: CONGRESSO BRASILEIRO DE CIÊNCIA DO SOLO, 27., 1999, Brasília. Anais... Brasília: Sociedade Brasileira de Ciências do Solo, 1999. 1 CD-ROM.

ASHIBURNER, J.E.; SIM, B.G. Elementos de diseño de labranza. São José: IICA, 1984. 473 p.

BALASTREIRE, L.A. Semeadura convencional. In: . Máquinas agrícolas. São Paulo:

Manole, 1990. cap 5., p.146-207.

BEKKER, C.F. Soil compaction pressures under rolling press wheels. Transactions of the ASAE, St. Joseph, v.2, n.1, p.63-4, 1956.

EMPRESA BRASILEIRA DE PESQUISA AGROPECUÁRIA. Serviço Nacional de Levantamento e Conservação de Solos. Manual de métodos de análise do solo. Rio de Janeiro, 1979. $58 \mathrm{p}$. 
EMPRESA BRASILEIRA DE PESQUISA AGROPECUÁRIA. Sistema brasileiro de classificação de solos. Rio de Janeiro, 1999. $412 \mathrm{p}$.

FURLANI, C.E.A.; LOPES, A.; REZENDE, L.C.; SOUZA E SILVA, S.S; LEITE, M.A.S. Influência da compactação do solo na emergência das plântulas de milho a diferentes profundidades de semeadura. Energia na Agricultura, Viçosa, v.9, n.3, p.147-53, 2001.

HARRIS, W.L. The soil compaction process. In: BARNES, K.K. (Ed.). Compaction of agricultural soils. Michigan: ASAE, 1971. p.9-44.

HUMMEL, J.W.; GRAY, L.E.; NAVE, W.R. Soybean emergence from field seedbed environments. Transaction of ASAE, St. Joseph, v.24, n.4, p.872-8, 1981.

MACHADO, R.L.; TURATTI, T.;ALONÇO, E.A.S. Construção e utilização de um perfilômetro. In: CONGRESSO BRASILEIRO DE CIÊNCIA DO SOLO, 24., 1993, Goiânia. Resumos... Sociedade Brasileira de Ciência do Solo, 1993. v.3, p.171-2.

MAH, M.M. Parâmetros físicos (Kc, Kf e $n$ ) referentes à resistência ao rolamento e suas relações com a umidade, em dois solos. 1980. 52 f. Dissertação (Mestrado em Mecanização Agrícola) Universidade Federal de Viçosa, Viçosa - MG, 1980.

MIALHE, L.G. Rodado e sistema de direção. In: . Máquinas motoras na agricultura. São Paulo: EPU, 1980. v.2., p.189-96.

PACHECO, E.P. Avaliação de uma semeadora adubadora de precisão com modificações no tubo condutor de sementes. 1994. 61 f. Dissertação (Mestrado em Mecanização Agrícola) Universidade Federal de Viçosa, Viçosa - MG, 1994.

SILVA, R.P. Efeito de rodas compactadoras submetidas a cargas verticais em profundidades de semeadura nas características agronômicas do milho (Zea mays L.). 2002. 119 f. Tese (Doutorado em Produção Vegetal) - Faculdade de Ciências Agrárias e Veterinárias, Universidade Estadual Paulista, Jaboticabal, 2002.

SILVA, R.P.; CORÁ, J.E.; LOPES, A.; FURLANI, C.E.A. Ação de rodas compactadoras de semeadoras submetidas a cargas verticais na deformação do solo. Ciência e Agrotecnologia, Lavras, v.29, n.4, p.839-47, 2005.

VIEIRA, L.B. Parâmetros físicos $\left(k c, k_{n}, n\right)$ referentes à resistência ao rolamento em nove solos sob duas condições de umidade. 1982. 45 f. Dissertação (Mestrado em Mecanização Agrícola) Universidade Federal de Viçosa, Viçosa - MG, 1982. 